\section{LA SOCIOHERMENÉUTICA COMO PROGRAMA DE INVESTIGACIÓN EN SOCIOLOGÍA}

\author{
Luis Enrique Alonso \\ Universidad Autónoma de Madrid \\ luis.alonso@uam.es
}

Cómo citar este artículo/ Citation: Alonso, L. E. (2013). “La sociohermenéutica como programa de investigación en sociología". Arbor, 189 (761): a035. doi: http://dx.doi.org/10.3989/ arbor.2013.761n3003

Recibido: 15 abril 2011. Aceptado: 25 octubre 2012.

RESUMEN: En este artículo hemos tratado de argumentar que la sociohermenéutica es una tradición propia del conocimiento sociológico desde el primer momento de formación de la sociología interpretativa clásica. Tradición totalmente diferente de la actual deconstrucción postmoderna y de su idea sobre el poder total del texto. Se revisan críticamente, a continuación, las aportaciones de Bourdieu al conocimiento de las prácticas lingüísticas como prácticas sociales de poder. Finalmente se define la lógica del análisis sociológico de los discursos - como análisis comprehensivo e interpretativo- como un tipo de trabajo específico que se separa tanto del análisis cuantitativo de contenido como del análisis estructural del texto de origen lingüístico.

PALABRAS CLAVE: Hermenéutica; sociología; análisis del discurso; texto; acción social; prácticas; lenguaje.

\section{SOCIO-HERMENEUTICS AS A RESEARCH PROGRAM IN SOCIOLOGY}

Copyright: (c) 2013 CSIC. Este es un artículo de acceso abierto distribuido bajo los términos de la licencia Creative Commons Attribution-Non Commercial (by-nc) Spain 3.0.
ABSTRACT: In this article we have tried to argue that socio-hermeneutics has been a tradition in itself in sociological knowledge since the inception of classical interpretative sociology. Its tradition is totally different from current postmodernist deconstruction and its ideas about the total power of text. Bourdieu's theories about linguistic practices such as social power practices are subsequently critically reviewed. Finally, the logic of the sociological discourse analysis (comprehensive and interpretative) is defined as a specific type of work which is separate from both quantitative analysis of content and structural text analysis of linguistic origins.

KEYWORDS: Hermeneutics; sociology; discourse analysis; text; social action; practices; language. 


\begin{abstract}
"Los actores son actores: reflexionan, actúan, nunca son totalmente adecuados para sus funciones y sus intereses, y la
\end{abstract} teoría debe poder explicar su actividad, su reflexividad, su crítica cuando tienen que resolver problemas"

Francos Dubet (2011)

\begin{abstract}
"Podemos referirnos a los sentidos y los significados como si estuvieran en cierto modo integrados en las cosas, o como si fueran la naturaleza que cada una de ellas tiene. Pero en la mayoría de los casos, los sentidos inherentes son simplemente
\end{abstract} los pedazos de nuestro lenguaje que llegan a lo que hay, a lo que está ahí"

Terry Eagleton (2007)

"La sociología no es una ciencia del espíritu [...] El hecho de que los fenómenos sociales estén mediados por el espíritu, por la conciencia de los hombres, no debe hacernos caer en el error de deducirlo sin más de un principio espiritual"

Theodor W. Adorno (2001)

El enfoque socioherméutico que vamos a tratar de desarrollar en estas páginas, asociado al análisis de los discursos en sociología, lo concebimos no tanto dentro del giro lingüístico del conocimiento contemporáneo, ni siquiera en el más genérico del giro interpretativo de las ciencias sociales contemporáneas (Rabinow y Sullivan, 1987: 15), sino como una tradición inscrita en la evolución de la sociología moderna desde su propia formación frente a la insistencia actual de que la hermenéutica se integraría en la investigación social en un momento postmoderno, de superación del positivismo y de vuelco del estudio de lo social en la deconstrucción de sus relatos y en el dibujo de sus cada vez más débiles identidades (Alvesson, 2002); en estas páginas se defiende un encuentro temprano entre la sociología y la hermenéutica como un auténtico programa de investigación en el sentido de Lakatos (1989), esto es, como un conjunto de reglas metodológicas, heurístico positivas unas y heurístico negativas otras, que nos definen cuáles son los senderos a seguir y cuáles los errores a evitar para la elaboración de nuestras prácticas y protocolos de investigación. En este programa de investigación nos encontramos con un conjunto de teorías interconectadas, ninguna de las cuales se puede considerar como totalmente autónoma sin hacer referencia al programa de investigación como un todo, lo que ayuda a construir la visión de la realidad que circunscribe el objeto de investigación y las reglas para operar con él. De esta forma, en este programa de investigación sociohermenéutico se pueden encontrar a lo largo de su evolución elementos principales que se han ido fortaleciendo y enriqueciendo desde su primera for- mación en el encuentro entre la sociología y la filosofía comprehensiva, así como un denso y creciente cinturón protector de hipótesis interpretativas extraídas de tradiciones intelectuales próximas, pero diferentes y de un conjunto de saberes prácticos acuñados en el campo de la investigación empírica.

\section{LA TRADICIÓN SOCIOHERMENÉUTICA}

El gran Georg Simmel, como es sabido, no encontraba para la sociología ningún nuevo objeto sustantivo, sino que la concebía como un "nuevo modo de observación", como un "punto de vista" o una mirada; una particular disposición de perspectivas gracias a la cual podemos vislumbrar lo significativo entre las, casi innumerables, formas y contenidos que configuran el denso mundo de lo social. La sociología apelaba, así, a las formas de conocimiento por las cuales el sujeto realiza la síntesis de los elementos que toma por "la sociedad"; pero, es más, si bien la síntesis descansa en el sujeto contemplador. Este es, a su vez, una síntesis de elementos de la propia sociedad; no es extraño, pues, que el propio Simmel le conceda un papel fundamental al proceso de socialización, como proceso según el cual los individuos establecen una unidad dentro de la que se realizan sus intereses, y que atribuya a la sociología el papel de la investigación de esas acciones recíprocas. Frente a la tentación individualista o psicologista, Simmel acaba otorgando a la realidad social un carácter interactivo, interpretativo y recíproco que se realiza en el proceso concreto de socialización; y a la sociología, el papel de estudiar, en cada contexto temporal y geográfico, el juego de 
posiciones y de relaciones sociales que se expresan y se despliegan a diferentes niveles, desde la conciencia individual hasta las estructuras institucionales.

Estos planteamientos se encuentran en el primer capítulo de la monumental monografía que Simmel dedicó a la sociología (Simmel, 1977: 14 y ss.). En el conocido ensayo: "El ámbito de la sociología", complemento inseparable de su imprescindible "El individuo y la libertad", Simmel se refiere al punto de vista de la producción social que estudia las "figuras que se producen en el marco de la interacción entre los hombres, o en ocasiones también ellas son tales interacciones, figuras que, así pues, no cabe considerar del individuo considerado por sí" (Simmel, 1986: 237). La sociología es, así, un método genético que se hace consciente de los tipos de producción social y estudia "la producción de fenómenos por medio de la vida social, y ciertamente en un doble sentido, por la coexistencia de individuos interactuantes que produce en cada uno lo que no es explicable a partir de él solo, y por la sucesión de las generaciones, cuyas herencias y tradiciones se amalgaman indisolublemente con la adquisición propia y hacen al hombre social" (ibídem). El propio Max Weber, contra todo naturalismo, hablaba de comprehender cómo captar la evidencia del sentido de cada actividad y relación -empleando, como bien ha recogido Julien Freund (1986: 85), el término de figura significativa-, e introducía, sobre la base de una subjetividad original, una racionalidad en lo real para poder interpretarlo y comprenderlo; el sentido considerado subjetivamente por los agentes tiene, así, resultados objetivos en el curso de toda actividad concreta. De este programa weberiano se pueden entresacar consecuencias permanentemente actuales para la sociología, tal como hace, por ejemplo, Miguel Beltrán: "El propósito de la sociología no es inventar el mundo social (lo es precisamente en el sentido latino del término), sino descubrirlo: conseguir que las realidades sociales sean también categorías sociológicas, ya que descubrir algo es sobre todo conceptualizarlo. [...] Construir conceptualmente la realidad es tanto como elaborar un mapa de la misma, mapa que no es la realidad ni su reflejo, pero que la representa, interpreta y hace inteligible. Y tal construcción existe siempre: o la hace la ciencia o la hace la ignorancia" (Beltrán, 1991: 60). Lo anterior nos liga, así, al enfoque del objeto de conocimiento; un objeto que debido, precisamente, al enfoque que propugnamos, se convierte y toma el papel de sujeto dentro de la investigación. La visión comprehensiva en sociología tiende, así, en primer lugar, a dar cuenta del horizonte de las formas simbólicas en donde se desenvuelven las acciones sociales; formas simbólicas que toman, convencionalmente, apariencia codificada -lenguajes-, pero de cuyo estudio, imprescindible, nos interesa no su gramática o estructura interna, sino su carácter comunicativo de mediador y formador de las experiencias y de las necesidades sociales (Lledó, 1996: 221); y, en segundo lugar, a examinar las producciones significativas de los propios sujetos - discursos, imágenes, relatos, representaciones, etc. - , generadas y construidas por los actores, o en el diálogo directo con ellos, en sus propios contextos situacionales, sociales e históricos; tratando, así, de evitar toda sobrecodificación o simplificación previa de los sentidos de la acción de los sujetos, típica del supuesto "observador objetivo externo".

Sobre esto, Norbert Elias se pronunció, con la brillantez y riqueza de matices que le caracteriza, cuando se refirió al "carácter doble del mundo de nuestra experiencia como un mundo independiente de nosotros, pero que nos incluye y como un mundo del que hace de intermediario para nuestro entendimiento una red de representaciones simbólicas hechas por el hombre, predeterminadas por su constitución natural, que solo se materializa con ayudas de procesos de aprendizaje social" (Elias, 1994: 195). Elias traza, de esta manera, un vínculo indisoluble que une lo social, lo simbólico, lo individual y hasta lo biológico, tratando de superar, así, cualquier intento de segregación radical de ámbitos; lo que sí parece posible es estudiar la contribución de cada ámbito, en su autonomía relativa, a la producción y a la reproducción de ese todo que consideramos realidad y que, a su vez, tiene tanto una dimensión fáctica, como una naturaleza simbólica construida. Los símbolos son, por tanto, esquemas de clasificación que las sociedades utilizan para construir un universo inteligible; de ahí que los símbolos vayan más allá de conceptos representacionales que se mueven bien en un horizonte exclusivamente lingüístico - el signo- o informático - la señal-, pues rompe el código cerrado de la lengua o de la convención prefijada para entrar en el mundo humano del sentido. Lo simbólico es una "apertura de mundo" y, por tanto, otorga igual que recibe el significado de las acciones sociales.

Por esto, coincidiendo con Paul Ricoeur, consideramos que la semántica del discurso envuelve y determina a la semiótica del signo; tomando el hecho mismo de comprender el carácter de una narración que sitúa al sujeto en un tiempo, y relacionándolo con el pasado y con el futuro (Ricoeur, 1991). Lo que nos interesa es, pues, la praxis intersubjetiva de los actores 
y no el sistema de la lengua como sistema abstracto; el habla concreta cobra sentido solo cuando se refiere a un contexto y a un juego de acontecimientos que regulan la polisemia de los símbolos y los articulan con acciones situadas. El discurso es, por lo tanto, algo más que una actualización o concreción de un sistema de signos, es una representación dinámica de la realidad realizada por su sujeto social.

Todo la anterior nos lleva, pues, a una visión sociohermenéutica de la sociología donde la interpretación no se plantea como un sistema hipotético deductivo que permite la verificación o falsación de un conjunto de categorías predeterminadas y codificables, (excluyendo como "ruido" todo lo que no se adapta al modelo de validación), sino como un proceso de captación de productos discursivos reales para tratar de determinar, en ellos, el sentido efectivo de la acción de los sujetos como sujetos sociales. La percepción, tanto de los actores como del investigador, son, así, elementos fundamentales de la interpretación, y el "ruido", lejos de ser excluido, es una parte de lo real que puede ser fundamental - como síntoma- para el análisis, al ser algo que entra en el campo continuo de lo analógico y que, sin embargo, queda literalmente fuera de las oposiciones binarias (verdadero/falso) de lo digital. Frente a la orientación fuertemente subjetivista que ha tenido la hermenéutica tradicional, la sociohermenéutica que aquí defendemos no busca tanto intuir o reconstruir el sentido auténtico y último que otorga un sujeto sublimado a sus enunciados simbólicos, sino los efectos reales que los discursos producen. Jean Phillipe Bouilloud (1997: 247), define la sociología como una hermenéutica de lo real, "en tanto que real social y este real social procede en sí mismo de la interpretación del mundo por los individuos" por ello, considera que la categoría básica de interpretación no es el sentido, sino el efecto del sentido; pues no es únicamente la voluntad de sentido lo que formalmente opera y lo que tiene relevancia en la comprensión, sino su percepción, recepción y retroacción en las interacciones de los públicos concretos. Berger y Kellner (1985: 59), por otra vía, llegan a una conclusión muy similar cuando aseguran: "no puedo interpretar el significado de otro sin cambiar, siquiera sea de modo mínimo, mi propio sistema de significado". Lo que en el estilo de hermenéutica preconizado por Charles Taylor viene a eliminar cualquier inflación de subjetivismo individualista, manejando la idea de que todo sentido es interpretable poniendo en relación los significados comunes que involucra en la colectividad (vid. Taylor, 1985: 47).
Apartándose, así, de cualquier dimensión ontológico-existencial, el encuentro entre hermenéutica y ciencias sociales se realiza sobre la idea de que el hecho de comprender no es nunca el comportamiento de un sujeto con un objeto dado, sino el acontecer de una acción histórica. El horizonte significativo, en el que hay que situar algo que se trata de interpretar en cuanto realidad cultural, no se puede nunca comunicar totalmente, ni agotar en todas sus dimensiones explicables; asimismo, lo interpretado está marcado por su acción en la historia; acción histórica que, a su vez, determina la conciencia del intérprete. En sociología, por tanto, el círculo hermenéutico toma la forma de un movimiento que comienza por un conocimiento inicial holístico de los sistemas de acción social, que es usado por el investigador, como base para interpretar las situaciones particulares, para luego volver a revisar los planteamientos generales en un proceso de permanente ajuste y diálogo entre las condiciones concretas de producción del sentido, y del sentido general que atribuye el intérprete (Herman, 1983: 58). Solo podemos interpretar un discurso si anticipamos su sentido en lo social, y esta anticipación será sucesivamente corregida cuando vayamos interpretando y analizando sus condiciones concretas de producción. La conversación entre los productos textuales y el intérprete es un intercambio de consciencias discursivas y de prácticas que converge en el trabajo de las ciencias sociales. Como indica Anthony Giddens (1984: 284; 1991: 201-221)), los teóricos sociales deben realizar interpretaciones con sentido de acciones que tienen sentido, pero estas, a su vez, modifican, en diferentes planos, la comprensión que los actores sociales tienen de su realidad social.

La interpretación hermenéutica tiende a la captación de los sentidos latentes y manifiestos de los procesos de interacción social, más allá de sus declaraciones convencionales. En principio, tales sentidos son la concreción de un proyecto de definición de las estrategias de los actores involucrados en el hecho a investigar, realizado por el propio sujeto investigador, mediador por su cultura, información, situación y percepción del campo social; proyecto de definición que será progresivamente objetivada por su contextualización en el conjunto de fuerzas sociales que enmarcan a los sujetos de la investigación, al investigador y a la investigación. Las estrategias de los actores, en suma, son inseparables de lo simbólico - un universo preconsciente de significados compartidos-; pues las acciones sociales en una parte sustancial están constituidas comunicativamente y solo comunicativamente pueden analizarse en su complejidad. Frente 
a cualquier naturalismo que presupone que las categorías de estudio se derivan del propio objeto de conocimiento, el carácter comunicativo de la interacción social obliga a la construcción concreta y estratégica de categorías que, desde la subjetividad del investigador, sean capaces de captar la subjetividad de los productos comunicativos de los actores, subjetividad que se constituye, finalmente, en intersubjetividad por el hecho mismo de que todo discurso se produce en sociedad y vuelve a ella (Le Moigne, 1995).

\section{SOCIOHERMENÉUTICA, MOTIVOS DE LA ACCIÓN Y RAZONES PRÁCTICAS}

El programa sociohermenéutico aspira a una reconstrucción de los motivos que operan en la conducta significativas de los agentes sociales. Pero eliminando, de entrada, cualquier connotación hipersubjetivista del concepto de motivación, así como cualquier tentación - tan al uso y abuso- de reducirlo solamente a las sobredeterminaciones inconscientes o biogenéticas de un individuo aislado, lo que acaba haciendo siempre, por un camino u otro, caer a este concepto en las ignotas esferas de la personalidad oculta o de la estructura biológica. Por el contrario planteamos, como es evidente, el concepto de motivación como un conjunto articulado de motivos concretos de acción y, entonces, como ha indicado pertinentemente el filósofo español Manuel Cruz, se produce un acercamiento importante entre la semántica situacional de la acción -típica de posiciones analíticas o postanalíticas - y la tradición hermenéutica de la Verstehen: "El nexo que se está proponiendo, en efecto, no es explicativo. Los motivos alegados constituyen una forma de interpretar la acción" (Cruz, 1995: 61).

Nexo de unión que hace ya más de cincuenta años, dejó apuntado C. Whrigt Mills en uno de sus tempranos y esclarecedores artículos sobre lenguaje, conocimiento y sociedad. Artículos un tanto olvidados, pero, hoy, afortunadamente rescatados por su anticipación a temas que la semántica de la acción está desarrollando en estos mismos momentos. De este modo, Ch. W. Mills (1981) proponía considerar los motivos, antes que como elementos fijados individualmente como términos socialmente preestablecidos con los que los actores sociales proceden a la interpretación de sus conductas. Abordando con ello la imputación y la declaración de motivos como fenómenos sociales a explicar, y no como el origen interno de ninguna acción externa. Se distinguirían, así, dos vías alternativas de acometer el tema de la motivación; una, la más convencional, que consiste en explicar las con- ductas en referencia a las motivaciones - consideradas como resortes subjetivos de la acción-, la otra, la más sociológica, que consiste en analizar los procesos lingüísticos observables de atribución y reconstrucción de motivos en cuanto que fenómenos sociales que deben interpretarse poniendo de manifiesto la relación de los vocabularios de motivos con los sistemas de acción social.

Aparece, por tanto, una concepción social de los motivos. Concepción que parte de la idea misma de que la explicación ordinaria de los motivos en el marco de las acciones situadas de los sujetos; y ello no es propiamente realizar una descripción de la experiencia personal de la acción, ni interpretar la acción y el discurso como manifestaciones externas de elementos subjetivos, sino buscar la forma en que los motivos socialmente construidos y las acciones tienen su origen en la situación en que los individuos particulares se encuentran. El elemento fundamental de este tipo de análisis es encontrar cómo se relacionan situaciones tópicas con repertorios de motivos apropiados a las conductas que en tal situación se producen. Los vocabularios de motivos, entonces, son repertorios lingüísticos diferentes, usados en situaciones diferentes, que varían históricamente y se encuadran en marcos sociales, siendo sus efectos finales hacer justificables las acciones ante los demás y ante el individuo mismo. La motivación deja así de tener un horizonte interno e individual, para convertirse en un espacio relacional que conecta con el lenguaje - materializado en repertorios y usos sociales concretos-, la subjetividad personal, la objetividad social y la intersubjetividad situacional.

De todas formas, interpretación, motivación y sociología cualitativa han sido, lógicamente, una constante en la tradición sociológica, fundamentalmente en su desarrollo comprehensivo; es el propio Max Weber el que contundentemente aseguraba, ya a principios del siglo veinte: "En el análisis del comportamiento humano, nuestra exigencia de explicación puede satisfacerse de modos cualitativamente diversos, es decir, de modos que dan una entonación cualitativamente distinta al concepto de irracionalidad. Para los fines de su interpretación podemos proponernos, al menos en principio, no solo 'concebirlo' como 'posible', en el sentido de hacerlo coherente con nuestro saber nomológico, sino también comprenderlo, es decir, reconstruir un 'motivo' o un complejo de motivos concretos 'reproducibles en la experiencia interior' y a partir de ello imputarlo con grados de precisión diversos según el material que dispongamos"(Weber, 1992: 80). 
Se trata, pues, de reconstruir en la investigación social cualitativa la intención de los sujetos implicados en la investigación; no se pretende, de esta manera, tomar las conductas como respuestas individualizadas de carácter acumulativo y externo, sino de comprenderlas en su sentido dinámico, como movimiento desde fuera hacia dentro, como interiorización o subjetivización de esquemas que, al estar determinados por las relaciones sociales, están fuera de los individuos o, cuando menos, no pertenecen solo al ámbito de lo individual. Como dice Pierre Bourdieu, desmarcándose tanto del objetivismo mecanicista como del subjetivismo espontaneísta, las motivaciones operan "como la interiorización de la exterioridad, permiten a las fuerzas exteriores ejercerse, pero según la lógica de los organismos en los que están incorporadas; es decir de manera duradera, sistemática y no mecánica: sistema adquirido de principios generadores" (Bourdieu, 1991: 95-96).

De esta manera, la sociología interpretativa/cualitativa busca y acepta las definiciones y significados del mundo social como dados $-\mathrm{y}$ reconstruye la realidad a través de la revelación de lo asumido como válido por los individuos y grupos del lugar-, pero solo a partir de su contextualización en otra dimensión. La dimensión que se preocupa de la identificación de los significados, no a partir de la descripción fáctica o de la aceptación del sentido común cotidiano, sino en la construcción del sentido de aquello que se observa desde el sistema de relaciones, esto es, entre acciones, palabras e imágenes como fuentes de significados. La motivación, así, no es un elemento psicológico o interno, sino el sentido de la acción situada en el campo relacional de los comportamientos humanos y por ello convertida en guía de la interpretación.

La interpretación de la motivación reclama, pues, la idea de un campo que ya desde sus versiones teóricas más antiguas -empezando por la de Kurt Lewin (1971), sintetizada allá por los años treinta, arrancando de la tradición gestalt-, supone el paso de un pensamiento en términos de sustancias a un pensamiento en términos de relaciones, lo que implica integrar el hecho de la motivación en el conjunto de las situaciones ambientales vividas por el individuo, así como su encaje en la dinámica de los grupos en los que interactúa (Feertchak, 1996: 104-115). La motivación, entonces, es más un resultado que un origen, y queda determinada por las relaciones con la estructura de fuerzas de la que forma parte, estando vinculados los cambios que experimenta a las modificaciones que sufren los demás componentes del cam- po en un espacio-tiempo determinado. Por su parte, Pierre Bourdieu le ha dado al concepto de campo una dimensión explícitamente sociológica, con mayores propiedades de estructuración objetiva de la acción, hasta convertirlo en campo de producción simbólica, es decir, un sistema de puestos, relaciones y competencias construido por un conjunto de agentes que unifican y legitiman las actuaciones individuales, encerrándolas en una frontera delimitada por la propia práctica de los agentes de ese dominio. El campo institucionaliza un punto de vista de las cosas y delimita el espacio de la motivación: "el proceso de diferenciación del mundo social, que conduce a la existencia de campos autónomos concierne, a la vez, al ser y al conocer: diferenciándose, el mundo social produce la diferenciación de los modos de conocimiento del mundo; a cada uno de los campos le corresponde un punto de vista fundamental sobre el mundo que crea su objeto propio y que encuentra en él mismo el principio de comprensión y explicación conveniente a este objeto"(Bourdieu, 1997: 119).

Hablar de motivación, pues, implica la posibilidad de aceptar la falta de conciencia explícita y presuponer que la conducta de los actores está determinada, o cuando menos influida, por fuentes no directamente accesibles de la conciencia (Giddens, 1987: 87); lo que nos lleva a la necesidad de utilizar prácticas o técnicas de investigación más abiertas que posibiliten al investigador considerar y evaluar lo no consciente de los sujetos a partir de lo que, con mayor o menor grado de libertad, conscientemente mantienen como sus objetivos e intenciones. Es decir, mediante el empleo de los métodos y técnicas cualitativas es posible acceder a las formaciones discursivas vivas, concretas y espontáneas, lo que, en último término, implica también entender que las declaraciones de los sujetos no expresan una identidad entre intenciones y acciones, sino que los discursos son una compleja expresión de niveles de la conciencia, donde la interpretación sociológica tiene que encontrar las relaciones entre lo consciente y lo preconsciente, entre lo declarativo y lo intencional, entre las racionalizaciones y las motivaciones, y, en suma, entre lo individual/instrumental y lo social expresivo. Nos encontramos ante una racionalidad interrogativa e interpretativa -toda proposición tiene más sentidos que su sentido declarativo- que no hace otra cosa que recoger el carácter problemático y problematizador de la realidad social como situación plural y múltiple (Meyer, 1995: 123 y ss.).

De esta manera, la sociohermenéutica se aparta, como programa de conocimiento social, del concepto 
de texto que maneja la deconstrucción postmoderna por resultar prácticamente inmanejable en las investigaciones sociales concretas. El texto omnipotente y separado de cualquier anclaje empírico o de referencia social operante, se convierte en el postmodernismo deconstructivista en una entidad inasible que, además se postula, por su capacidad de diseminación y el diferimiento de la significación, como una especie de anti-realidad absoluta y opresora (Eagleton, 2005). Sin embargo, el discurso, solo tiene sentido en la investigación hermenéutica concreta como una práctica simbólica que se construye en $-y$ construye a- los actores sociales en el juego de representaciones de sus conflictos, intereses y formas de historicidad concretas. Todo ello nos lleva a las razones prácticas y a los nichos de la vida intersubjetivamente creados, frente a un concepto de texto o incluso metatexto del que nada puede salir y que se convierte - a pesar del radicalismo inicial de la propuesta deconstructivista y de la ironía contra las verdades de la interpretaciónen un concepto de tintes autoritarios. No tanto por sus posibles repercusiones políticas - que las puede tener - como por su incapacidad de dejar cualquier libertad de acción-reacción, interpretación y crítica a los sujetos en sus realidades concretas. Cargar los tintes como hace la deconstrucción en una lectura que, por ser infinitamente arriesgada, de hecho no tiene el más mínimo riesgo, al poder decir y desdecir todo en un canto a la arbitrariedad absoluta y autocomplaciente, cuyo valor para la investigación social es prácticamente nulo. Los discursos no son solo palabras, son formas de práctica social que nos remiten a luchas y jerarquías políticas, a contextos pragmáticos, a nichos institucionales, a condiciones materiales y a prácticas no discursivas en un sentido estricto. Los discursos -y su interpretación- nos remiten, pues, a «razones prácticas», en el sentido que le da a este concepto Pierre Bourdieu (1994 y 1997), es decir, al conjunto de relaciones entre la posición y la toma de posición. En consecuencia, en sociedad, existen límites de posibilidad de los discursos y límites de sus interpretaciones -límites históricos, políticos, económicos, situacionales, etc. - , de manera que la mayor o menor plausibilidad de los discursos y sus interpretaciones vienen del mayor y mejor reconocimiento contextual de esos límites, aunque sea para superarlos o subvertirlos.

Es evidente que la aportación de Pierre Bourdieu al acercamiento entre la sociología y la lingüística ha sido enorme. Además, como desde muchos puntos de vista se ha argumentado, la disciplina tradicional de la sociolingüística como marchamo académico regularizado se había venido dedicando más a problemas estrictamente lingüísticos (cambio o variación lingüística, ideolectos y sociolectos, nacionalismo y lenguaje, hipercorrección, habla común, cualquier otro tema de la influencia de lo social sobre el lenguaje) que a temas de corte realmente sociológico. En este sentido el trabajo de Bourdieu por romper los principios de inmanencia lingüística que se arrastran desde Saussure y que ha lanzado al estudio del lenguaje por una especie de "lingüística del cerebro" (realizada sobre sistemas de oposición y de transformación lógica) ha sido contundente y hasta fascinante, sobrepasando con mucho las posiciones más avanzadas de la etnolingüística y la sociolingüística norteamericanas, fuertemente influidas por el interaccionismo simbólico y, por tanto, mucho más centradas en los procesos de construcción lingüística de la microsituación social que en demostrar, como pretende Bourdieu, que los códigos lingüísticos son parte de un capital simbólico que, a su vez, valoriza, produce y reproduce lo social genérico.

\section{PIERRE BOURDIEU Y SU CRÍTICA A LA HERMENÉU- TICA: POSIBILIDADES Y LIMITACIONES}

Bourdieu, como se sabe, se opone nominalmente a la tradición hermenéutica por su supuesta resistencia a la objetivación, el canto desbocado del punto de vista -que deprecia los constreñimientos del campo-, su ambivalencia humanística que puede acabar en peligrosas maniobras filosóficas como el caso Heidegger, su acientifismo romántico y literario o su fetichización de la lengua (Bourdieu, 1988). Y frente a esta representación de la tradición hermenéutica un tanto prejuicial y deformada, el sociólogo francés se sitúa en la tradición prácticamente opuesta del hecho social durkheimiano -objetivo, externo, que se impone sobre los sujetos-, que tanta importancia ha tenido en la propia formación del paradigma estructuralista en la lingüística, aunque Bourdieu haga su teoría en directa oposición a tal visón estructural. La concepción que presenta Bourdieu del lenguaje (Bourdieu, 1985; Bourdieu y Boltanski, 1975) como mercado lingüístico, o sea, como un sistema de diferencias y valores lingüísticos ordenados en (y por) el campo social de referencia en que los actores plantean sus jugadas de sentido, no deja de funcionar como una especie de capitalismo lingüístico (no hay otra cosa detrás de su noción de mercado lingüístico) con diferencias y valores expresivos ordenados y reproducidos por el sistema de dominación social (Bourdieu y Wacquant, 2005: 211-219); cargándose de una especie de funcionalismo de la dominación y con escasas - por no decir nulas - aperturas a la praxis o al dialogismo. 
La inteligente maniobra de Bourdieu, muchas veces más terminológica que real, de atribuir al habitus y fundamentalmente al habitus lingüístico el carácter, no solo de estructura estructurada, sino el de estructura estructurante (es decir, formadora de prácticas), no deja de seguir otorgando un carácter excesivamente reproductivista al plan de análisis social propuesto por el propio Bourdieu (Martín Criado, 2010; Lahire, 2002). Centrar, como hace nuestro autor, el análisis del discurso casi exclusivamente en la violencia simbólica, planteado como una reconstrucción necesitante, frente a la comprensión participante de, por ejemplo, la hermenéutica contemporánea, nos lleva peligrosamente hacia el monologismo: un monologismo crítico y denunciador de la dominación, pero monologismo al fin y al cabo. Esta es una crítica habitual que se despliega desde diferentes círculos de orientación hermenéutica; de este modo, nos encontramos con la típica argumentación, entre heideggeriana y liberal, de Luc Ferry y Alain Renaut (1988: 34), donde afirman que Bourdieu corre el riesgo de caer en una caricatura que le incitó a reducir, sin otra forma de proceso, el sentido de toda diferencia comunicativa de una voluntad social de distinción, acabando con cualquier posibilidad de libertad o creación positiva de sentido, hasta el argumento que el propio Gadamer utiliza en respuesta directa a Bourdieu, de que su crítica a la hermenéutica acaba por reducir cualquier diálogo humano, filosófico o existencial a la expresión de una voluntad social de legitimación de la desigualdad o de eufemistización de las estrategias de dominación en el campo cultural (Gadamer, 2002: 341-355).

En la idea de la reconstrucción necesitante (Bourdieu, 1995: 442-443) hay una pretensión de objetivismo y descripción (denuncia) del campo de fuerzas que ha producido las expresiones lingüísticas -los discursos son necesarios en un campo conflictivo-, que deja fuera las capacidades de interpretación de los actores -empezando, como pretende Gadamer (1998: 11-27), por interpretarse a sí mismos en diálogo con sus propios enunciados - o las posibilidades de acción comunicativa del lenguaje de los sujetos sociales, donde no solo se pone en juego un interés instrumental, sino también un interés hermenéutico o incluso un interés emancipatorio. Abrir el mundo del lenguaje al dialogismo es, sin obviar el marco de la dominación social, apreciar también las capacidades de autoorganización y autorreflexión de los sujetos, de construcción y atribución del sentido por parte de los propios actores y no solo la descripción de cómo los sentidos de los poderosos se imponen a los dominados (Habermas, 1991). Es evidente que el desafío hermenéutico en las ciencias sociales está planteado y, como dice Zygmunt Bauman (2002: 226), "la verdad de la sociología debe ser negociada, de igual manera que lo es el consenso corriente; y las más de las veces no son los sociólogos quienes establecen las reglas de la negociación".

$Y$ es que, aunque se haya pretendido lo contrario - ver por ejemplo Burkitt (1998) - , es este bloqueo de Bourdieu para pensar lo dialógico en todas sus versiones el que genera la imposibilidad estructural de nuestro autor para acercarse, desde sus planteamientos epistemológicos y metodológicos, a conceptos imprescindibles en el análisis sociológico de los discursos como es el de la polifonía o el mundo de la vida cotidiana (Alonso, 1998; Alonso, 2009). Así, en consecuencia con estos planteamientos, que se arrastran en la obra de Bourdieu desde la época de libros como El oficio del sociólogo (en el que se plantea el conocimiento como una conquista contra el sentido común, una doxa con la que hay que cortar y separase en la crítica (Bourdieu, Chamboredon y Passeron, 1989), todo lenguaje "popular" es considerado como una ausencia de poder, esto es, entendiéndolo por el poder que no tiene, porque en la homología con la economía que aquí se despliega, tienen escaso capital simbólico o lingüístico. Todo lo contrario al planteamiento de Mijail Bajtin (1982) donde todo acto lingüístico es un acto que necesita al otro, como otro concreto, que implica ideología, pero por eso mismo implica acción, creación y reacción, praxis social que se produce desde todos los espacios de la estructura social.

Ya frontalmente contra Bourdieu, Michel de Certeau $(1990,82-97)$ se pronuncia contra la imagen de radical pasividad para la creación de sentido que tiene el concepto de práctica en Bourdieu, prisionero del habitus y reducido a usos lingüísticos planteados como supuestas estrategias para ganar poder que, por variados que se presenten, son eternamente reproductivos, calculadores, estratégicos. Pero de Certeau - y otros autores - nos recuerdan también el carácter gratuito y de don que tienen muchos de nuestros actos culturales y lingüísticos: la comunicación es estrategia, pero también es cooperación y donación; es reproducción, pero también es reconstrucción, reelaboración e incluso invención a partir de materiales preexistentes. En la condición de sujeto está la condición de productor de narraciones, narración que unifica sustancialmente a prácticas culturales, lingüísticas, sociales, etc. Cada producción, diría de Certeau, es una reelaboración, una redefinición desde la experiencia, que implica no solo aceptación 
sumisa, sino resistencia creativa. Bourdieu, por tanto, había planteado muy bien la dimensión dominación simbólica del lenguaje, pero se despreocuparía de la dimensión donación y cooperación o de incluso de la dimensión reconstrucción y resistencia, algo que no se puede dejar fuera en los juegos pragmáticos que toda práctica comunicativa comporta. Michel de Certeau indica, además, que estas operaciones de utilización o reutilización simbólica corresponden al antiguo arte del "hacer": son usos, designando con ello acciones que tienen sus propias lógicas y sentidos, y que organizan callada y cotidianamente el trabajo del consumo de producción cultural. Con Bourdieu hemos sabido que el análisis sociológico de los discursos no solo mostrando las relaciones que se mantienen con un sistema o un orden no solo lingüístico, sino también social delimitando las relaciones de fuerza lenguaje y la comunicación, pero también debemos dar cuenta del encaje de sentidos y poderes que no se derivan solo del sistema de dominación sino de la capacidad de los sujetos de activarse e interpretarse, quizás así podamos dar sentido a ese proyecto de democratización de la postura hermenéutica que Bourdieu (1999: 542) quería reivindicar frente a la tradición convencional e hipersubjetiva de interpretar descontextualizadamente los textos literarios o los grandes productos culturales de héroes o antihéroes de la creación formal, sino una lectura comprehensiva de los relatos corrientes de las gentes corrientes.

\section{SOCIOHERMENÉUTICA, TEXTO Y DISCURSO}

El mismo concepto de texto, incluso etimológicamente - trama de hilos-, remite a multiplicidad, a un entramado o urdimbre. Texto es un entramado de palabras entrelazadas, unidas en una disposición regularizada que le proporciona su consistencia comunicativa que representa la materialización social de discursos como líneas de enunciación simbólica que nos remiten a posiciones sociales. En efecto, en su enfrentamiento con el formalismo lingüístico, Bajtín definió el carácter dialógico e intertextual de todo enunciado: "Ios enunciados no son indiferentes uno a otro, ni son autosuficientes, sino que saben uno de otro y se reflejan mutuamente. Estos reflejos recíprocos son los que determinan el carácter del enunciado. Cada enunciado está lleno de ecos y reflejos de otros enunciados con los cuales se relaciona por la comunidad de la esfera de la comunicación discursiva" (Bajtin, 1982: 264). El problema, entonces, no es la estructura subyacente de la lengua, sino la significación social del habla, y esta significación es producto siempre de un diálogo, o de un proyecto de diálogo que, desde la propia formación de la mente como proceso psicológico superior -operando en el aspecto simbólico y no solo sobre el sistema de señales-, construye lo humano como social y, por lo tanto, como una conversación o un diálogo de múltiples voces.

En el enfoque sociohermenéutico, por tanto, el lenguaje aparece no como el agente de la creación exclusiva de la realidad social, creación que se derivaría de la potencia constitutiva de sus códigos, sino como el medio de construcción significativa del mundo en una situación concreta, a partir de las experiencia de los actores sociales. Esta constitución ayuda a crear significados libres, a partir de la interacción de biografías próximas que soportan en su actuación la visión del mundo de biografías remotas, pero encuadradas en el mismo grupo de pertenencia. Una construcción que se realiza por negociación (Cicourel, 1981, 1982) desde la posición social (de poder) de los sujetos de la enunciación, y no solo por la imposición de códigos.

El trabajo de la sociohermenéutica, entonces, no es un análisis de textos, ni lingüístico, ni psicoanalítico, ni semiológico; no se busca en él la estructura subyacente de la enunciación, ni la sintaxis combinatoria de las unidades significantes, sino es la reconstrucción del sentido de los discursos en su situación - micro y macro- de enunciación. Más que un análisis formalista, se trata en este enfoque sociohermenéutico - tan cercano a la fenomenología como a la teoría críticaen el que la reconstrucción de los intereses de los actores nos aparece como modelo de comprensión del texto grupal, en su contexto social y en la historicidad de sus planteamientos. La tarea interpretativa consiste, pues, en incorporar a la propia interpretación la interpretación del otro; la hermenéutica se hace doble hermenéutica en cuanto que es la reflexión del analizador sobre el actor y del actor sobre el analizador (Giddens, 1984, 1991).

El análisis sociohermenéutico no es, por tanto, el desmigajamiento de un corpus buscando sus unidades de significación elementales; lo que no quiere decir que el corpus no tenga que ser minuciosamente leído y releído, seleccionado y ordenado realizando un recorte en sus sentidos posibles, según los objetivos de la investigación, sino que es la sistematización de ese corpus, por un modelo concreto de representación, lo que le otorga significación a los enunciados. Modelo que, como Piaget sugirió en su estudio de las estructuras cognitivas (Piaget, 1986), opera por un doble proceso; por una parte de asimilación -integración de los enunciados en el modelo-, y por otra, de adaptación - transformación del esquema en función 
de los resultados enunciativos-; constructivismo concreto que marca la metodología ad hoc de la investigación social cualitativa, cuando esta es realizada en su dimensión más creativa (Conde, 2010; Ortí, 2000).

Por lo tanto, más que con "el texto", en el análisis sociohermenéutico, trabajamos con nuestras textuales empíricas, que se producen no sobre la hipótesis de aleatoriedad, individualidad e independencia, sino sobre la idea de que el campo discursivo donde los discursos son coherentes con su contexto, a la vez que son, o pueden ser, interdependientes, estratificados, competitivos y conflictivos entre sí. La labor del investigador social, en este tipo de práctica cualitativa, no es, por tanto, un análisis sintáctico o lingüístico de textos, sino el análisis pragmático centrado en los usos y los efectos y, por ello, de reconstrucción crítica de los procesos ideológicos generadores de esos textos producidos en los contextos sociales de enunciación. El análisis de los textos producidos en condiciones sociales es siempre sociohermenéutico, puesto no es una simple utilización mecánica de la amplia caja de herramientas heredadas de la metodología lingüística o semiótica, sino el uso estratégico y orientado en su sentido de esas herramientas en el marco siempre concreto, completo y complejo del contexto temático de la investigación social. El proceso ideológico se asocia, así, al análisis de los productos discursivos propiamente dichos, el análisis no es, por tanto, un análisis "interno" - tal como se ha pretendido desde la semiótica formal-, sino un análisis de articulación de mensajes explícitos, con unas reglas de comprensión y de adecuación que son antes sociales que lingüísticas. La ideología no se encuentra en la descomposición de la frase - trabajo que Roland Barthes (1981) le atribuía al lingüista-, ni es una función específica del lenguaje, sino que se combina y entremezcla en todas sus funciones para encontrar (o simplemente buscar), un poder social (Rossi-Landi, 1980).

Toda lectura de un enunciado es una interpretación $y$, por tanto, al igual que cualquier proceso de interpretación es infinito, como se han encargado de recordarnos repetidamente, desde posiciones cercanas a la hermenéutica fenomenológica, autores como HansGeorg Gadamer o Paul Ricoeur. El trabajo de lectura y análisis de un grupo de discusión no es un análisis de contenido - un recuento de frecuencias de los términos aparecidos, o bien de los trenes o diferenciales semánticos como modelo externo de asociación y correlación de palabras (Bardin, 1986) - , ni un análisis de texto en el que se busca un modelo abstracto del que se genera, o deduce, la enunciación concreta.
Antes, habría que conceptualizarlo como un análisis estratégico, modulado por los objetivos de la investigación, en el que hay un proyecto de reconstruir, en su contexto concreto, las prácticas significantes de los sujetos de la enunciación. Proceso que, siguiendo al crítico norteamericano Frederic Jameson (1989: 48), podemos conceptualizar como una reescitura fuerte del texto; pues no es tanto una decodificación como una transcodicicación lo que se hace en la interpretación, ya que lo que se busca con ella no es encontrar la coherencia del texto, sino el lugar que lo comunicativo ocupa en la creación y recreacción de la realidad social de los discursos.

El texto, como producto cultural, cobra relieve cuando se lee en su materialidad social; esto es, cuando se inscribe en los determinantes que están en su génesis, en las relaciones de poderes que lo enmarcan y en los efectos innovadores o reproductores que origina (Wiliams, 1994). La investigación social siempre y en todo lugar exige un paso hermenéutico, por cuanto que el proceso de entendimiento interpretador que lo anima implica la consideración, tanto de los investigadores como de los investigados como sujetos. Sujetos, además, en el mismo plano de lo social a lo largo de toda la investigación. El análisis del discurso no es una técnica objetivo-explicativa, puesto que hay intersubjetividad desde la misma selección del texto, sino una práctica relacional-reflexiva. El conocimiento aparece como proceso no como resultado. El investigador se convierte así en instrumento metodológico fundamental. Es aquí donde la perspectiva cualitativa se encuentra con el uso del concepto de "verstehen" de Dilthey y Weber, como intento del investigador de lograr un conocimiento del sentido de la acción del actor en orden a reconstruir el fenómeno social. De este modo, esta mirada desde la "verstehen" solo puede tener sentido de interpretación reflexiva; por una parte porque conecta la acción de cada individuo a la de los demás miembros de la sociedad en un doble sentido - en cuanto que los individuos son capaces de participar por la vía de ciertos roles y reflejarlos en el producto de esa participación, pero a la vez quedar reflejados por ellos-; por otra parte porque los investigadores quedan definidos en la misma investigación al puntualizar el sentido de las acciones de los sujetos, desde su propio sentido de la acción. La interpretación se convierte en necesaria, y por esto no se puede percibir el fenómeno social como un valor inmediato y superficial sino en su interpretación desde su profundización crítica. El mismo José Ortega y Gasset lo expresaba con rotundidad en su conocido prólogo a "Introducción a las ciencias del espíritu", la "opera 
magna" de Wilhem Dilthey (1980:24): "La ciencia es el descubrimiento de las conexiones entre los hechos. En la conexión el hecho desparece como puro hecho y se transforma como miembro de un 'sentido'. Entonces se le entiende. El sentido es la materia inteligible". El conocimiento se transforma por la práctica, tanto como la práctica se ve transformada por el conocimiento.

Esta visión nos introduce directamente en un enfoque crítico-racional de la investigación, donde la aproximación a la realidad social debe llevarse a cabo mediante la introducción, consciente y críticamente orientada, de la esfera de los valores y de los fines sociales en el proceso de investigación; cuestionando, de forma permanente mediante un proceso "autorreflexivo", la aparente neutralidad e inmediatez de los discursos (Habermas 1982: 197 y ss.). El análisis sociológico de los discursos es imposible que trabaje con un criterio analítico-sistémico; por su propia naturaleza de herramienta metodológica pretecnológica, concreta, intensiva y no estadística tiene una segura vinculación de base con un criterio crítico de investigación en las ciencias sociales. Esto es fácil de ver claramente, siguiendo a Jürgen Habermas (1973: 117180), cuando opone los rasgos definitorios de ambas corrientes en lo que se refiere a su concepción del proceso de investigación social. Frente a la primacía de la determinación y contrastación técnica de hipótesis particulares mediante definiciones operativas (formalizables y medibles por instrumentos técnicos) que propone el método analítico (lo que supone, de hecho, la primacía del método sobre el objeto de conocimiento), el método crítico, contempla la primacía de la comprensión y explicación teórica global de los procesos sociales en movimiento mediante totalidades concretas y representaciones globales tomadas como procesos discursivos; aquí es siempre el objeto particular el que determina y tiene primacía sobre el método. Los acontecimientos son situados en su lugar histórico, pero no como simple producto derivado, sino a través de la experiencia vivida de sus actores. La interpretación, a la vez, es cercanía - ponerse en el lugar del sujeto- y es distancia - ponerse en el contexto de enunciación-; no hay modelo objetivo de interpretación, hay siempre subjetividad objetivada y objetividad subjetivada (Gadamer, 1993):

La sociohermenéutica circunscribe el espacio propio para el análisis sociológico de los discursos, separándolo del análisis lingüístico de los textos, o de la sistematización analítica de los mismos, por cuanto que deben de plantearse con lógicas diferentes. Ignorar estas diferencias lógicas, mezclándolas o queriendo reducirlas todas a una -en el análisis del discurso lo habitual ha sido reducir lo social a lo lingüístico- crea errores de todo tipo; básicamente errores de interpretación, pero errores, al fin y al cabo, que provienen de no asentar de manera correcta los fundamentos epistemológicos del análisis de discurso en sociología. El lenguaje, desde aquí, toma un sentido polimorfo, activo y convencional, fruto de múltiples acciones humanas, y sus usuarios son los que actúan en el lenguaje, de forma que el significado de un término es sencillamente su uso en un determinado juego del lenguaje que se corresponde con una forma concreta de vida; por eso, en el contexto que justifica el uso, es donde se encuentra la posibilidad de la comprensión, y no en los fundamentos lógicos de las palabras o de las reglas donde se sitúa la producción del sentido en el lenguaje (Wittgenstein, 1988: 33 y ss).

El estudio de los discursos, tal como aquí se plantea, se pregunta lo que hace y busca la gente cuando utiliza el lenguaje - de ahí su dimensión fundamentalmente pragmática-; investiga regularidades sociales y no "leyes" formales; se centra en la tematización más que en la sintaxis significante; encuentra referencias a contextos, más que universales, lingüísticos o antropológicos; opera por analogía e interpretaciones locales y no por digitalización y protocolos genéricos; $y$, finalmente, el "corpus", lejos de ser la prueba textual o el hecho positivo de la interpretación, es la vía para la comprensión de la función interactiva y comunicativa de los discursos: "el analista del discurso trata su "corpus" como el registro (texto) de un proceso dinámico en el cual el hablante/escritor utiliza el lenguaje como instrumento de comunicación en un contexto para expresar significados y hacer efectivas sus intenciones (discurso). Trabajando sobre estos datos, el analista intenta describir las regularidades encontradas en las realizaciones lingüísticas que emplea la gente para comunicar esos significados e intenciones" (Brown y Yule, 1993: 47).

Nos encontramos, por tanto, no en el espacio del análisis formal, sino en el de la interpretación; en esa situación mezcla de "sospecha y escucha" que trata de penetrar en el significado para los sujetos de los enunciados, sin subordinar los enunciados a las leyes, sean estas estadísticas o lingüísticas (Ricoeur, 1986:151). El análisis del discurso como análisis sociohermenéutico es un análisis pragmático del texto y de la situación social - micro y macro- que lo ha generado. El trabajo sociohermenéutico parte, así, de que no buscamos códigos universales, sino el significado de las acciones 
de los sujetos sociales. Vamos del texto a la acción, del enunciado al sentido de lo vivido por los sujetos. Si el modelo lingüístico se utiliza en el plano de la constitución de los enunciados, el modelo hermenéutico fenomenológico, que estamos diseñando, se coloca en el plano de la fundamentación de los enunciados: intención, motivación, sentido, etc. (Ricoeur, 1988: 133-154). Fundamentar las acciones conlleva averiguar qué significan para los que las realizan y, con ello, tratar de situarse en el lugar de los sujetos, en este caso de los actores sociales. Ponerse en el lugar de los actores no significa, por un lado, usurpar el papel de esos actores, ni, por otro, adoptar la posición única de uno de los actores en juego, sino entrar en un campo de fuerzas que no es armonioso sino conflictivo; es un campo comunicativo y, por ello, es un juego de poderes y un juego de lenguajes.

La interpretación sociológica de los discursos, no es, por tanto, un análisis de contenido - tomado este como suma de los significados prefigurados de las palabras que componen el texto-, ni un análisis formal - se realice en el plano sintáctico, morfológico, estilístico, fónico, o semántico-, sino un análisis contextual, donde los argumentos toman sentido en relación con los actores que los enuncian, enmarcados en un conjunto de fuerzas sociales en conflicto que los originan. El hacer interpretativo, es un querer saber sobre el hacer de los discursos, esto es, una práctica de atribución de sentido de los discursos centrada sobre lo que los discursos hacen en sociedad. Esto representa, justamente, lo contrario de una lectura analítica de los textos - que trata de encontrar un perfil estructural dividiendo su texto en partes y subpartes-; es una lectura activa, en la que las preguntas que se le hacen al texto se realizan desde una polifonía de las diferentes posiciones sociales que entran en el campo social de referencia. Toda interpretación se efectúa en un conflicto de interpretaciones, porque toda interpretación se hace en la encrucijada de la pluralidad de sentidos de lo social (Ricoeur, 1995). Si siguiendo al inolvidable Maurice Merleau-Ponty (1993: 191 y ss.), podemos distinguir la palabra hablada - producto lingüístico sistematizado y cristalizado- de la palabra hablante - manifestación de un lenguaje en su sentido creador - la interpretación sociológica se mueve en este último plano, por cuanto la labor del lenguaje no se estudia como producto final, sino en tanto que vehículo de captación y comunicación de los sentidos referidos al marco social de los mensajes. La interpretación, por tanto, es el descubrimiento del sentido, pero no de una manera arbitraria, de imposición del yo sobre cualquier realidad - como pretendería cual- quier proposición solipsista o nihilista del hacer interpretativo-, sino de encuentro intersubjetivo entre el sujeto como generador de sentido y el mundo de la vida en que se encuentra como límite de los significados: "Esto equivale a decir que nosotros damos su sentido a la historia, pero no sin que ella nos lo proponga" (Merleau-Ponty, 1993: 457).

El camino de la interpretación, de esta manera, no nos debe conducir a ninguna arbitrariedad del autor de dicha interpretación: como viene diciendo Umberto Eco desde hace ya más de treinta años, el lector no puede usar el texto como desee, sino como el texto quiera ser usado (Eco, 1993: 77-82). Es decir, la interpretación adquiere sentido cuando reconstruye, con relevancia, el campo de fuerzas sociales que ha dado lugar a la investigación, y cuando su clave interpretativa es coherente con los propios objetivos concretos de la investigación; un doble enfoque pragmático pragmática de los discursos sociales, pragmática de la estrategia de la investigación- que nos aleja definitivamente de cualquier formalismo lingüístico o matemático, como de cualquier anhelo de sobreinterpretación.

Teniendo en cuenta que cuando hablamos, aquí, de sobreinterpretación no estamos usando el concepto en su acepción restringida o técnica, tal como lo viene utilizando, por ejemplo, el psicoanálisis clásico freudiano (Laplanche y Pontalis, 1984: 413), esto es, como una interpretación más profunda o derivada que se desprende, de modo secundario, de una interpretación primera - coherente y completa ya en sí misma-, y que vendría determinada por la superposición de estratos de significación en los procesos y productos de la vida psíquica; procesos en los que la condensación de una sola imagen expresa varias series inconscientes de desarrollo simbólico. Antes, al contrario, consideramos la sobreinterpretación en su acepción de interpretación insostenible, descontextualizada y excesiva, guiada más por la intención unívoca del receptor que por la postulación coherente de una intención del texto. De acuerdo con esto, podemos decir, con Umberto Eco, que el mensaje puede acoger una multiplicidad de significados y referentes, pero no tenemos derecho a decir que puede significar cualquier cosa, o mejor, efectivamente, "puede significar cualquier cosa, pero hay sentidos que sería ridículo sugerir" (Eco, 1995: 47).

Interpretación, entonces, que da prioridad a la práctica sobre el código; a la función sobre la estructura; al contexto sobre el texto; a lo latente sobre lo inconsciente; a la intencionalidad del mensaje sobre 
la arbitrariedad de los signos y, en suma, a la primacía de la comunidad o del contexto histórico social sobre la comprensión de un mensaje, teniendo en cuenta el carácter problemático y conflictivo de ese contexto (Hymes, 1973:4-5). Todo análisis social en los textos empieza siendo un mapa de posiciones discursivas que trata de representar un campo comunicativo que, a la vez, es un campo de fuerzas sociales. Las categorías de análisis aparecen, así, no por un proceso de lógica composicional - de determinación de un modelo que se adapta a unas reglas universales-, sino de estructuración prototípica, esto es, una organización global de las propiedades típicas de los discursos que son reconocidas en, y por, los hablantes. Es una organización cognitiva de categorías que trata de representar las propiedades y atributos más importantes desde el punto de vista social de los enunciados, referidos a una situación real y concreta (Kleiber, 1995:67).

\section{CONCLUSIÓN}

El investigador cualitativo, en tanto que analizadorinterprete de discursos es un metodólogo pragmático, despliega su práctica de investigación como si fuera un sistema de estrategias y de operaciones "ad hoc"; llamadas - en todo momento- para conseguir respuestas a determinadas preguntas concretas sobre la agenda de temas que le interesan en su investigación específica (Strauss, 1987: 17; Strauss y Corbin, 2005). La realidad se reconstruye, no se recoge; se describe o se refleja como si estuviera simplemente ahí fuera, y el investigador la descubriese en su exterioridad absoluta, como pretenden los positivistas o neopositivistas más o menos feroces; ni tampoco se inventa desde la creatividad arbitraria del texto o de la mirada absoluta del observador, como pretenden las diversas corrientes postmodernos al uso y abuso; más bien, hay que decir que toda realidad se construye de manera subjetiva con materiales y con límites que son objetivos. Esto quiere decir que toda interpretación, por el hecho de serlo, ni refleja, ni traduce "la realidad" - ni mucho menos, a nivel más particular, la naturaleza objetiva del texto-, sino que trata de descubrir, de la manera más completa posible, la trama de significados que reconstruye una realidad a la que el investigador, de manera coherente con su proyecto - objetivos particulares, contextos de acción y posición socialencuentra sentido en cuanto intérprete. Como dice Gadamer, el mundo de lo humano no es algo dado, no es un objeto explicado por categorías científicas directamente aplicables, sino que es una experiencia vivida en cuanto "horizonte"; mirada que trata de abrir -y también fijar - los límites de la acción: "El mundo es en este sentido para nosotros un espacio sin límites, en medio del cual estamos y buscamos nuestra modesta orientación"(Gadamer, 1997:118) Esto nos Ileva al tema del posible subjetivismo de la labor sociohermenéutica, sin embargo, el subjetivismo, antes de considerarlo como un obstáculo para la investigación, hay que estimarlo como una de sus precondiciones necesarias, pues es el sujeto quien atribuye sentido a los hechos y a los textos. Así, Z. Bauman (2002), en su magnífico texto sobre hermenéutica y sociología, observaba que los contenidos asociados a las prácticas culturales solo se pueden entender en relación a los contenidos de la propia cultura - siempre hay traducción-; lo que se puede entender más como una ventaja que como una desventaja. Hay que recalcar, de este modo, que la posición creativa del analista es central, aunque esté raramente reconocida y siempre tiene un límite objetivado y objetivador en referencia al campo y los contextos de acción. Podemos acordar con Paul Ricoeur (1990), que el juicio que se refiere a la interpretación es una conjetura, y que la validación de la interpretación es antes el fruto de su adaptación a una praxis conflictiva, derivada del contexto de la interpretación, que el producto de una lógica universal de la verificación empírica tan aséptica como irreal.

Esta hegemonía del nivel de la interpretación es fundamental si concebimos el trabajo del investigador social no como un simple descriptor de fenómenos sociales puntuales asociados por relaciones externas, sino como un sujeto en proceso que busca en las conductas humanas acciones significativas; acciones cuyo sentido, para el conjunto de actores involucrados en ese campo, trata de extraer conceptualmente. Si la pretensión analítica es sustituir el estudio de la dinámica de la acción de los agentes por un más o menos minucioso proceso de acumulación de hechos, discretos, convertidos en datos de sus productos, y el deseo estructuralista es el de reducir los acontecimiento a sus invariantes universales, lo importante de esta visión hermenéutica es hallar los mecanismos que vinculan las estructuras a los acontecimientos. La sociohermenéutica por tanto se ha demostrado como un potente núcleo unificador en tanto que conjunto de teorías que tratan de dar cuenta de la central importancia del sentido, el sujeto, el símbolo y el discurso en la dinámica de lo social -así como en su investigación sistemática-, y que reúnen los logros más notables en ese campo de conocimiento. Núcleo que ha ido produciendo un complejo cinturón protector de hipótesis auxiliares que han estado reiteradamente sometidas a un contraste permanente con los hechos y las representaciones sociales. Todo esto 
ha hecho de este encuentro entre la hermenéutica y la sociología un programa de investigación científico progresivo, gracias a las sucesivas reformulaciones de sus aplicaciones, que han supuesto un aumento de su contenido empírico. Como cualquier programa de in- vestigación, la sociohermenéutica no tiene una forma perpetua, sino que es provisional y cambiante, podrá ir tanto desembarazándose de hipótesis desgastadas como añadiendo hallazgos heurísticos que lo hagan más eficaz para la investigación social.

\section{BIBLIOGRAFÍA}

Adorno, Th. W. (2001). Epistemología y ciencias sociales. Madrid: Cátedra.

Alonso, L. E. (2005). La era del consumo. Madrid: Siglo XXI de España Editores.

Alonso, L. E. (2009). Prácticas económicas y economía de las prácticas. Crítica del postmodernismo liberal. Madrid: Libros de La Catarata, 262 pp.

Alonso, L. E.; Martín Criado, E. y Moreno Pestaña, J. L. (2004). Pierre Bourdieu, Las herramientas del sociólogo. Madrid: Fundamentos, 398 pp.

Alvesson, M. (2002). Postmodernism and Social Research. Buckingham: Open University Press.

Bajtin, M. (1982). Estética de la creación verbal. México: Siglo XXI.

Bardin, L. (1986). Análisis de contenido. Madrid: Akal.

Barthes, R. (1981). "Introduction à l'analyse structurale des récits». En AA. VV., L'analyse structurale du récit. París: Seuil/Points, pp. 7-33.

Bauman, Z. (2002). La hermenéutica y las ciencias sociales. Buenos Aires: Nueva Visión.

Beltrán, M. (1991). La realidad social. Madrid: Tecnos.

Berger, P. L. y Kellner, H. (1985). La reinterpretación de la sociología. Madrid: Espasa-Calpe.

Bouillourd, J. Ph. (1997). Sociologie et société. Épistemologie de la réception. París: Presses Universitaires de France.

Bourdieu, P. (1985). ¿Qué significa hablar? Economía de los intercambios lingüísticos. Madrid: Akal.

Bourdieu, P. (1988). La ontologie politique de Martin Heidegger. París: Minuit.

Bourdieu, P. (1991). El sentido práctico. Madrid: Taurus.

Bourdieu, P. (1994). Raisons pratiques. Sur la théorie de l'action. París: Seuil.
Bourdieu, P. (1995). Las reglas del arte. Génesis y estructuras del campo literario. Barcelona: Anagrama.

Bourdieu, P. (1997). Méditations pascaliennes. París: Seuil.

Bourdieu, P. (1999). "Comprender". En Bourdieu, P. (dir.), La miseria del mundo. Madrid: Akal, pp. 527-543.

Bourdieu, P. y Boltanski, L. (1975). Le fetichisme de la lange. Actes de la recherche en sciences sociales, $\mathrm{n}$ - 4, pp. 2-35.

Bourdieu, P. y Wacquant, L. (2005). Una invitación a la sociología reflexiva. Buenos Aires: Siglo XXI.

Bourdieu, P.; Chamboredon, J. C. y Passeron, J. C. (1989). El oficio de sociólogo. Madrid: Siglo XXI.

Brown, G. y Yule, G. (1993). Análisis del discurso. Madrid: Visor.

Burkitt, I. (1998). "The Death and Rebirth of the Author: The Bakhtin Circle and Bourdieu on Individuality, Language and Revolution". En Gardiner, M. y Bell, M. M. (eds.), Bakhtin and the Human Sciences. No last words. Londres: Sage, $\mathrm{pp}$. 198-219.

Certeau, M. de (1990). L'invention du quotidian. Paris: Folio/Gallimard.

Cicourel, A. (1981). "Notes on the Integration of Micro -and Macro- Levels of Analysis". En Knorr-Cetina, K. y Cicourel, A. (eds.), Advances in Social Theory and Methodology. Boston: Routlege and Kegan Paul, pp. 21-59.

Cicourel, A. (1982). El método y la medida en sociología. Madrid: Editora Nacional.

Conde, F. (2010). Análisis sociológico del sistema de discursos. Madrid: Centro de Investigaciones Sociológicas.

Cruz, M. (1995). ¿A quién pertenece lo ocurrido? Acerca del sentido de la acción humana. Madrid: Taurus.

Dilthey, W. (1980). Introducción a las ciencias del espiritu. Madrid: Alianza, con prólogo de José Ortega y Gasset.
Dubet. F. (2011). La experiencia sociológica. Barcelona: Gedisa.

Eagleton, T. (2005). Después de la teoría. Barcelona: Debate.

Eagleton, T. (2007). The Meaning of life. Oxford: Oxford University Press.

Eco, U. (1993). Lector in fábula. La cooperación interpretativa en el texto narrativo, Barcelona, Lumen, 3a ed.

Eco, U. (1995). “Interpretación e historia”. En Eco, U. y otros, Interpretación y sobreinterpretación. Cambridge: Cambridge University Press, pp. 25-47.

Elías, N. (1994). Teoría del símbolo. Un ensayo de antropología cultural. Barcelona: Península.

Feertchak, H. (1996). Les motivations et les valeurs en psycho-sociologie. París: Armand Colin.

Ferry, L. y Renaut, A. (1988). Heidegger et les modernes. París: Grasset.

Freund, J. (1986). Sociología de Max Weber. Barcelona: Península.

Gadamer, H. G. (1993). El problema de la conciencia histórica. Madrid: Tecnos.

Gadamer, H. G. (1997). “La diversidad de las lenguas y la comprensión del mundo". En Koselleck, R y Gadamer H., Historia y hermenéutica. Barcelona: Paidós Ibérica, Edición de José Luis Villacañas y Faustino Oncina.

Gadamer, H. G. (1998). El giro hermenéutico. Madrid: Cátedra.

Gadamer, H. G. (2002). Los caminos de Heidegger. Barcelona: Herder.

Giddens, A. (1991). "Structuration theory, past, present and future". En Bryant, Ch. y Jary, D. (eds.), Giddens' theory of structuration. A critical appreciation. Londres: Routledge, pp. 201-221.

Giddens, A. (1984). The Constitution of Society. Outline of Theory of Structuration. Berkeley: University of California Press. 
Giddens, A. (1987). Las nuevas reglas del método sociológico. Buenos Aires: Amorrortu.

Habermas, J. (1973). "Teoría analítica de la ciencia y dialéctica". En Theodor W. Adorno y otros, La disputa del positivismo en la sociología alemana. Barcelona: Grijalbo, pp. 147-181.

Habermas, J. (1982). Conocimiento e interés. Madrid: Taurus.

Habermas, J. (1988). La lógica de las Ciencias Sociales. Madrid: Tecnos.

Habermas, J. (1991). Conciencia moral y acción comunicativa. Barcelona: Península.

Herman, J. (1983). Les langages de la sociologie. París: Presses Universitaires de France.

Hymes, D. (1973). Foundations in Sociolinguistics. Londres: Tavistock.

Jameson, F. (1989). Documentos de cultura, documentos de barbarie. La narrativa como un acto socialmente simbólico. Madrid: Visor.

Kleiber, G. (1995). La semántica de los prototipos. Categoría y sentido léxico. Madrid: Visor.

Lahire, B. (2004). El hombre plural. Los resortes de la acción. Barcelona: Bellaterra.

Lakatos, I. (1989). La metodología de los programas de investigación científica. Madrid: Alianza.

Laplanche, J. y Pontalis, J. B. (1984). Diccionario de psicoanálisis. Barcelona: Labor.

Le Moigne, J. L. (1995). Les épistémologies constructivistes. Presses Universitaires de France.
Lewin, K. (1971). Field Theory in Social Science. Nueva York: Harper and Row.

Lledó, E. (1996). Lenguaje e historia. Madrid: Taurus, ed. aumentada.

Martín Criado, E. (2010). La escuela sin funciones. Crítica de la sociología de la educación crítica. Barcelona: Bellaterra.

Merleau-Ponty, M. (1993). Fenomenología de la percepción. Barcelona: Planeta/ Agostini.

Meyer, M. (1995). Of Problematology. Chicago: The University of Chicago Press.

Mills, C. W. (1981). "Acciones situadas y vocabularios de motivos". En Poder, política, pueblo. México: Fondo de Cultura Económica, reimp., pp. 345-356.

Ortí A. (2000). "La apertura y el enfoque cualitativo estructural: la entrevista abierta semidirectiva y la discusión de grupo". En García Ferrando, M.; Ibáñez, J. y Alvira, F. (eds.), El análisis de la realidad social. Alianza: Madrid, pp. 219-282.

Piaget, J. (1986). Estudios sociológicos. Barcelona: Planeta-Agostini.

Rabinow, P. y Sullivan, W. M. (1987). "The Interpretive Turn". En Rabinow, Paul y Sullivan William M. (eds.), Interpretive Social Science. A Second Look. Berkeley: University of California Press.

Rancière, J. y otros (1994). L'empire du sociologue. París: La Découverte.

Ricoeur, P. (1988). El discurso de la acción. Madrid: Cátedra.

Ricoeur, P. (1990). Soi-même comme un autre. París: Seuil.
Ricoeur, P. (1991). Historia y verdad. Madrid: Encuentro.

Ricoeur, P. (1995). Teoría de la interpretación. Discurso y excedente de sentido. México: Siglo XXI/Universidad Iberoamericana.

Rossi-Landi, F. (1980). Significato, comunicazione, parlare comune. Padova: Marsilio.

Searle, J. R. (2001). Mente, lenguaje y sociedad. Madrid: Alianza.

Simmel, G. (1977). Sociología. Estudios sobre las formas de socialización. Madrid: Revista de Occidente, 2 vols.

Simmel, G. (1986). El individuo y la libertad. Ensayos de crítica de la cultura. Barcelona: Península.

Strauss, A. L. y Corbin, J. (2005). Grounded Theory in Practice. Thousand Oaks: Sage, $2^{a}$ ed.

Strauss, A. L. (1987). Qualitative Analysis for Social Scientist. Nueva York: Cambridge University Press.

Taylor, Ch. (1985). Human Agency and Language. Cambridge: Cambridge University Press.

Weber, M. (1992). El problema de la irracionalidad en las ciencias sociales. Madrid: Tecnos, 2ªedición.

Williams, R. (1994). Sociología de la cultura. Barcelona: Paidós.

Wittgenstein, L. (1988). Investigaciones filosóficas. México/Barcelona: UNAM/ Crítica. 